\title{
Study on the Preparation and Electrochemical Properties of Nano ZnO/polyaniline Composite Anticorrosive Coating
}

\author{
Zijun Liao ${ }^{1, a}$, Chuxiao Lin ${ }^{1, b}$, Changjiang Yang ${ }^{1, c}$, Yifan Jia ${ }^{1, d}$, Peng $\mathrm{Wu}^{1, \mathrm{e}}$, \\ and Sen Qiao ${ }^{1, f}$
}

\author{
Logistical Engineering University, Chongqing, 401311, China

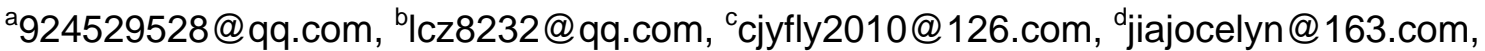 \\ e49945924@qq.com, ${ }^{\mathrm{f}} 845725425 @ q q . c o m$
}

\begin{abstract}
Keywords: polyaniline, nano $\mathrm{ZnO}$, anticorrosion.
Abstract. A nano $\mathrm{ZnO}$ /polyaniline composites was obtained in situ polymerization of polyaniline nano zinc oxide surface, using ammonium persulfates as the oxidant, through a silane coupling agent $\mathrm{KH} 550$. And the secondary Doped Nanometer $\mathrm{ZnO}$ /polyaniline was obtained using $\mathrm{HCl}$, phosphoric acid and sulfosalicylic acid. The relative magnitude of the conductivity of different acids in $1 \mathrm{~mol} / \mathrm{L}$ was studied. A new anticorrosive coating was obtained by blending the relatively higher electrical conductivity of $\mathrm{ZnO}$ /polyaniline doped by $\mathrm{HCl}$ and sulfosalicylic acid with the epoxy resin, then the corrosion resistance of the coating was analyzed by open circuit potential (OCP) and Tafel curve. The results showed that, nano $\mathrm{ZnO} /$ polyaniline exhibited better corrosion resistance compared with single polyaniline coating.
\end{abstract}

\section{Introduction}

Metal corrosion is the phenomenon that the surface of the metal material and the environmental media have chemical and electrochemical action, which cause the degradation and destruction of the material. The economic loss caused by metal corrosion in our country is hundreds of billions of dollars every year, so it is very important to study the protection of metals from corrosion. For a long time, people have been using a variety of techniques to protect metal from corrosion. Among them, one of the most effective and commonly used methods for the corrosion protection of metal equipment is to coat the metal surface with anti-corrosion coating, in order to isolate the corrosion medium and the metal substrate [1-2]. Polyaniline coating has many advantages, such as an easy access to raw materials, simple synthesis, no pollution, etc., and it also has a unique anti-scratch and pitting corrosion resistance, widely used in marine, aviation and other special fields [3-5].But because the polyaniline is a chain of strong interaction of conjugated macromolecule, its solubility and adhesionon on the basis is poor, coupled with its high economic cost, insoluble properties, polyaniline can not be directly processed by the traditional method, and its application is limited to a large extent. Polyaniline composites prepared from polyaniline and matrix composites with good mechanical properties, which can overcome the shortcomings of poor processing performance of polyaniline, improve its anti-corrosion properties.

Due to the small size and large specific surface area of the nanoparticles, the quantum effect of the nano particles is endowed with many special properties. In a large number of nano oxides, nano $\mathrm{ZnO}$ has a high melting point, excellent corrosion resistance, excellent ultraviolet screening property and excellent bactericidal deodorant [6-7]. Application of nano $\mathrm{ZnO}$ in coating and preparation of new functional coatings are expected to improve the anti-corrosion of traditional coatings and other properties, such as the adhesion of composite coatings, the impact resistance of composite coatings, the flexibility of composite coatings, the resistance to aging of composite coatings, etc..

In this paper, the eigenstates nano $\mathrm{ZnO} /$ polyaniline was prepared by chemical oxidation in situ polymerization. The nano $\mathrm{ZnO} /$ polyaniline composite was prepared by doping hydrochloric acid, phosphoric acid, and sulfosalicylic acid with nano $\mathrm{ZnO}$ /polyaniline, and the relative magnitude of the electrical conductivity of different acids in $1 \mathrm{~mol} / \mathrm{L}$ was studied. 


\section{Experimental Sections}

materials and instruments. Aniline: analytically pure (Chengdu Kelong Chemical Reagent Factory); Nano Zinc Oxide: analytically pure (Chengdu Huaxia Chemical Reagent Co., Ltd.); Ammonium persulfate (APS): analytically pure (Tianjin Kermel Chemical Reagent Co., Ltd.); Hydrochloric acid $(\mathrm{HCl})$ : chemically pure (Tianjin Kermel Chemical Reagent Co. Ltd.); Phosphoric acid $\left(\mathrm{H}_{3} \mathrm{PO}_{4}\right)$, analytically pure, Chongqing East Sichuan Chemical Co., ltd.; Sulfosalicylic acid (SSA): chemically pure (Tianjin kwangfu Technology Development Co., Ltd.); HG-13 epoxy resin (EP) (Zhong Hao dawn chemical), etc..

The conductivity of the sample was measured using MITSUBISHI MCP-T610 low impedance analyzer, and then the sample was pressed into a circular specimen with a diameter of $20 \mathrm{~mm}$ under the tablet machine pressure of $30 \mathrm{MPa}$; An intelligent instrument for coating thickness measuremen-QuaNix4500 (Germany Automation Dr. Nix GmbH); Sand grinding and dispersing mixer (Shanghai Modern Environmental Engineering Technology Co., Ltd.); the electrochemical workstation-PARSTAT 2273 (American Princeton Applied Research Company), the electrochemical workstation adopted three electrode working system, the working electrode was a coating sample, the auxiliary electrode was a platinum electrode, and the reference electrode was a silver/silver chloride electrode, and the electrolyte was a $3.5 \mathrm{wt} \%$ sodium chloride $(\mathrm{NaCl})$ solution.

Preparation of nano $\mathrm{ZnO}$ /polyaniline composites doped with different acids. A $6.8 \mathrm{ml}$ aniline and $1 \mathrm{~mol} / \mathrm{L} \mathrm{HCl}$ solution were added in a three necked flask, then ice bath stirring for ten minutes, adding $5 \mathrm{~g}$ nano zinc oxide treated by $\mathrm{KH} 550$, until the temperature dropped to $5^{\circ} \mathrm{C}$, we used the dropping funnel dripped slowly add the prepared over the mixed solution of ammonium sulfate and hydrochloric acid. After titration, the mixture was kept in ice-cooling while stirring for 7 hours. The $\mathrm{pH}$ value of the solution maintained at 1.50 in the reaction process. Then the product was filtered and washed, and was dried under vacuum conditions, The original doped nanometer $\mathrm{ZnO}$ /polyaniline was obtained, which was dark green powder. The original doping polyaniline sample was added $0.1 \mathrm{~mol} / \mathrm{L}$ ammonia to remove $\mathrm{HCl}$, at room temperature and stirred for $6 \sim 8$ hours. After filtration and washing the eigenstates nano $\mathrm{ZnO} / \mathrm{PANI}$ was obtained. The same method was used to prepare the polyaniline without $\mathrm{ZnO}$.

The $1 \mathrm{~mol} / \mathrm{L} \mathrm{HCl}, \mathrm{H}_{3} \mathrm{PO}_{4}$ and SSA solutions were prepared. They were respectively added to the eigenstates of nano $\mathrm{ZnO} / \mathrm{PANI}$ samples, stirred with magnetic force for a certain amount of time. After filtration washing for several times and dried under vacuum conditions, $\mathrm{HCl}$ and $\mathrm{H}_{3} \mathrm{PO}_{4}$ and SSA doped composite samples were obtained, and marked as $\mathrm{HCl}+\mathrm{ZnO}, \mathrm{H} 3 \mathrm{PO} 4+\mathrm{ZnO}, \mathrm{SSA}+\mathrm{ZnO}$. According to the same method, the samples of polyaniline doped with $1 \mathrm{~mol} / \mathrm{L}$. SSA, H3PO4 and HCl were prepared, marked as $\mathrm{HCl}, \mathrm{H} 3 \mathrm{PO} 4$ and SSA.

Corrosion resistance of nano $\mathrm{ZnO}$ /polyaniline anticorrosive coating. The nano $\mathrm{ZnO} /$ polyaniline and epoxy resin were mixed in proportion, and a proper amount of curing agent were added, and the coating was prepared. Wiped the No. 304 stainless steel plate $(20 * 80 * 1 \mathrm{~mm})$ with acetone to remove grease, then the steel plate was dried. Anticorrosive coating was sprayed on the surface of clean steel plate, controlling the film thickness in the 200 around $\mu \mathrm{m}$, drying at a temperature below $60^{\circ} \mathrm{C}$ for $8 \mathrm{~h}$. After the steel plate was dried, it was dipped into $3.5 \% \mathrm{NaCl}$ solution. The open circuit potential (OCP) and the Tafel curve (Tafe1) [9] were measured with PARSTAT 2273 electrochemical workstation, and the corrosion resistance of the composite coatings was characterized.

\section{Results and Discussion}

Effect of different acid doping on the conductivity of nano $\mathrm{ZnO}$ /polyaniline doped with two times. The conductivities of $1 \mathrm{~mol} / \mathrm{L}$ different protonic acid doping with nano $\mathrm{ZnO} /$ polyaniline and polyaniline, which was utilized as comparison, were shown in Table 1. As it can be seen from the table 1 , the conductivity of doped nano $\mathrm{ZnO}$ /polyaniline had a certain degree of improvement compared with the conductivity of polyaniline, and the enhancement of organic proton acid SSA was higher than that of inorganic proton. This may be due to the volume of organic proton acid SSA larger than that of the inorganic proton, and the large molecule proton acid was doped into the polyaniline, 
which made the conformation of polyaniline molecules and molecules more conducive to the charge of the chain, which was conducive to the increase of the conductivity of nano $\mathrm{ZnO} /$ polyaniline[10,11].

Table 1 Electrical conductivity of two times doping $\mathrm{ZnO} /$ polyaniline doped with different acids

\begin{tabular}{ccccccc}
\hline Sample & $\mathrm{HCl}+\mathrm{ZnO}$ & $\mathrm{HCl}$ & $\mathrm{H}_{3} \mathrm{PO}_{4}+\mathrm{ZnO}$ & $\mathrm{H}_{3} \mathrm{PO}_{4}$ & $\mathrm{DSSA}+\mathrm{ZnO}$ & $\mathrm{SSA}$ \\
\hline Conductivity[S $\left.\cdot \mathrm{cm}^{-1}\right]$ & 1.94 & 1.45 & 0.58 & 0.16 & 3.72 & 2.94
\end{tabular}

Open circuit potential (OCP) of nano $\mathrm{ZnO}$ /polyaniline composite anticorrosive coating. Due to the increase of the conductivity of $\mathrm{ZnO}$ /polyaniline doped with organic acid, two types of $\mathrm{ZnO}$ /polyaniline doped with $\mathrm{HCl}$ and SSA were selected to research on electrochemical properties, which had a larger conductivity. Figure 1 was OCP curves of different polyaniline coating in $3.5 \mathrm{wt} \% \mathrm{NaCl}$ solution with the change of soaking time, the blank sample was exposed steel plate. As can be seen from Fig. 1, in the early immersion, the open circuit potential of the 5 kinds of steel plate all decreased; Along with the increase of immersion time, the open circuit potential moved toward the anode direction gradually and the change tended to be gentle. The exposed steel plate had the lowest open circuit potential, and the steel plate with the film was obviously moved to the anode. The results showed that the polyaniline coating could form a dense oxide passivation layer on the surface of the steel plate, which could effectively isolate the contact between the corrosion material and the steel plate, and achieve a better corrosion protection effect [12]. In Fig. 1, the nano $\mathrm{ZnO}$ /polyaniline anticorrosion coating doped with $\mathrm{HCl}$ was compared with the polyaniline anticorrosive coating doped with $\mathrm{HCl}$, the open circuit potential was increased and the movement of the anode was more obvious. The open circuit potential of nano $\mathrm{ZnO}$ /polyaniline anticorrosive coating doped with SSA was larger than that of the polyaniline coated with SSA, which was closer to the anode. The result showed that nano $\mathrm{ZnO}$ could increase the open circuit potential due to its strong corrosion resistance, thus we can infer that the composite of polyaniline and nano $\mathrm{ZnO}$ have good passivation ability and good anti-corrosive effect.

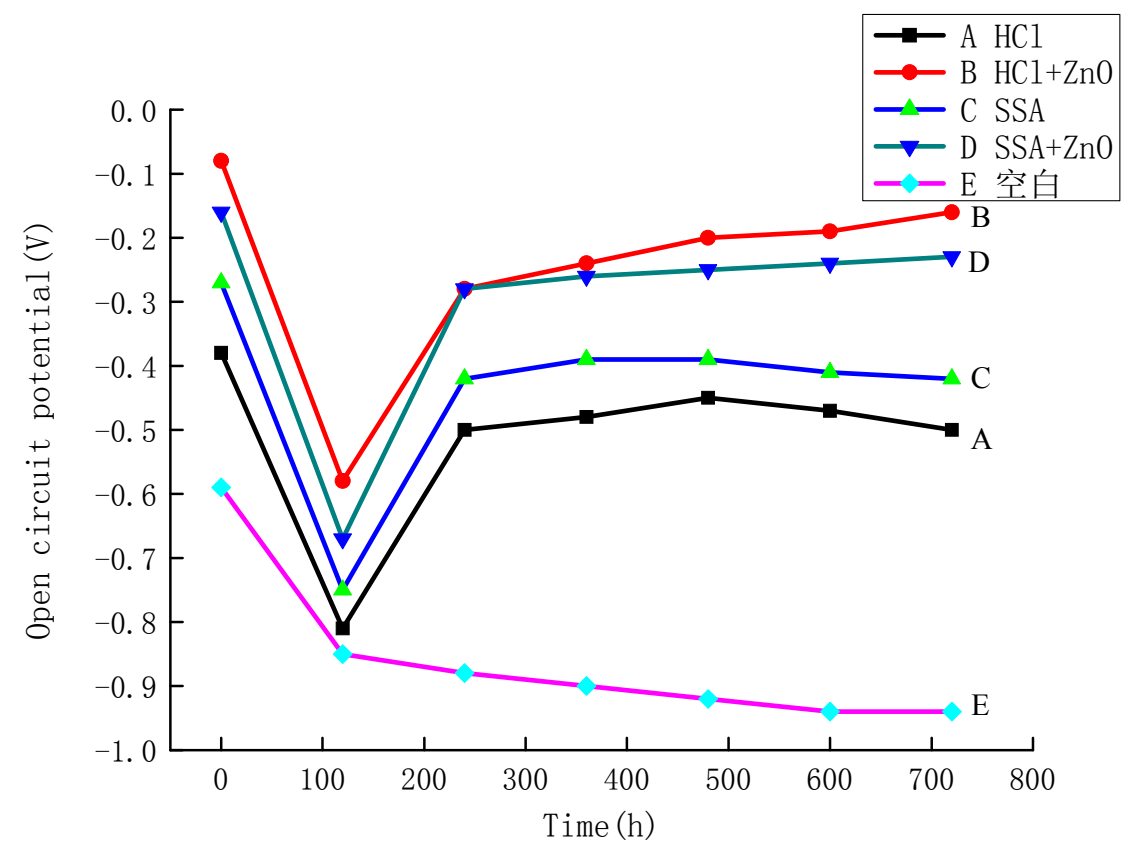

Fig.1 Open circuit potential curves of different composite coatings

Tafel curve of nano ZnO/polyaniline composite anticorrosive coating. Fig. 2 shows the Tafel curves of different polyaniline composite coating in $3.5 \mathrm{wt} \% \mathrm{NaCl}$ solution after soaking in $720 \mathrm{~h}$ solution, The corrosion current (icoor) and corrosion potential (Ecoor) were obtained by fitting the measured Tafel curves, as shown in Table 2. From Fig. 2 and table 2, we can see that compared to the nanometer $\mathrm{ZnO} /$ polyaniline anticorrosive coating doped with $\mathrm{HCl}$, the corrosion current of the 
polyaniline anti-corrosion coatings doped with $\mathrm{HCl}$ fell by $0.016 \mu \mathrm{A}$, and the corrosion potential increased by $29.9 \mathrm{mV}$. Identically, compared to the nanometer $\mathrm{ZnO} /$ polyaniline anticorrosive coating doped with SSA and polyaniline anti-corrosion coatings doped with SSA, the corrosion current also fell by $0.277 \mu \mathrm{A}$, the corrosion potential increased by $53.41 \mathrm{mV}$. It can be concluded that the corrosion resistance of nano $\mathrm{ZnO} /$ polyaniline anticorrosion coating is better than that of polyaniline anticorrosive coating. The results showed that the addition of nano $\mathrm{ZnO}$ could effectively improve the corrosion resistance and the corrosion rate of the polyaniline coating. Among all the samples, the nano $\mathrm{ZnO}$ /polyaniline anticorrosion coating doped with $\mathrm{HCl}$ had the lowest corrosion current and the highest corrosion potential, which indicated that this anti-corrosion coating had the highest corrosion resistance.

Table.2 Eleetroehemieal parameter of Tafel curves

\begin{tabular}{ccccc}
\hline Sample & A & B & C & D \\
\hline $\mathrm{i}_{\text {coor }}\left(\mathrm{nA} / \mathrm{cm}^{2}\right)$ & 0.452 & 0.436 & 1.045 & 0.768 \\
$\mathrm{E}_{\text {coor }}(\mathrm{mV})$ & -125.39 & -95.49 & -150.45 & -97.04 \\
\hline
\end{tabular}

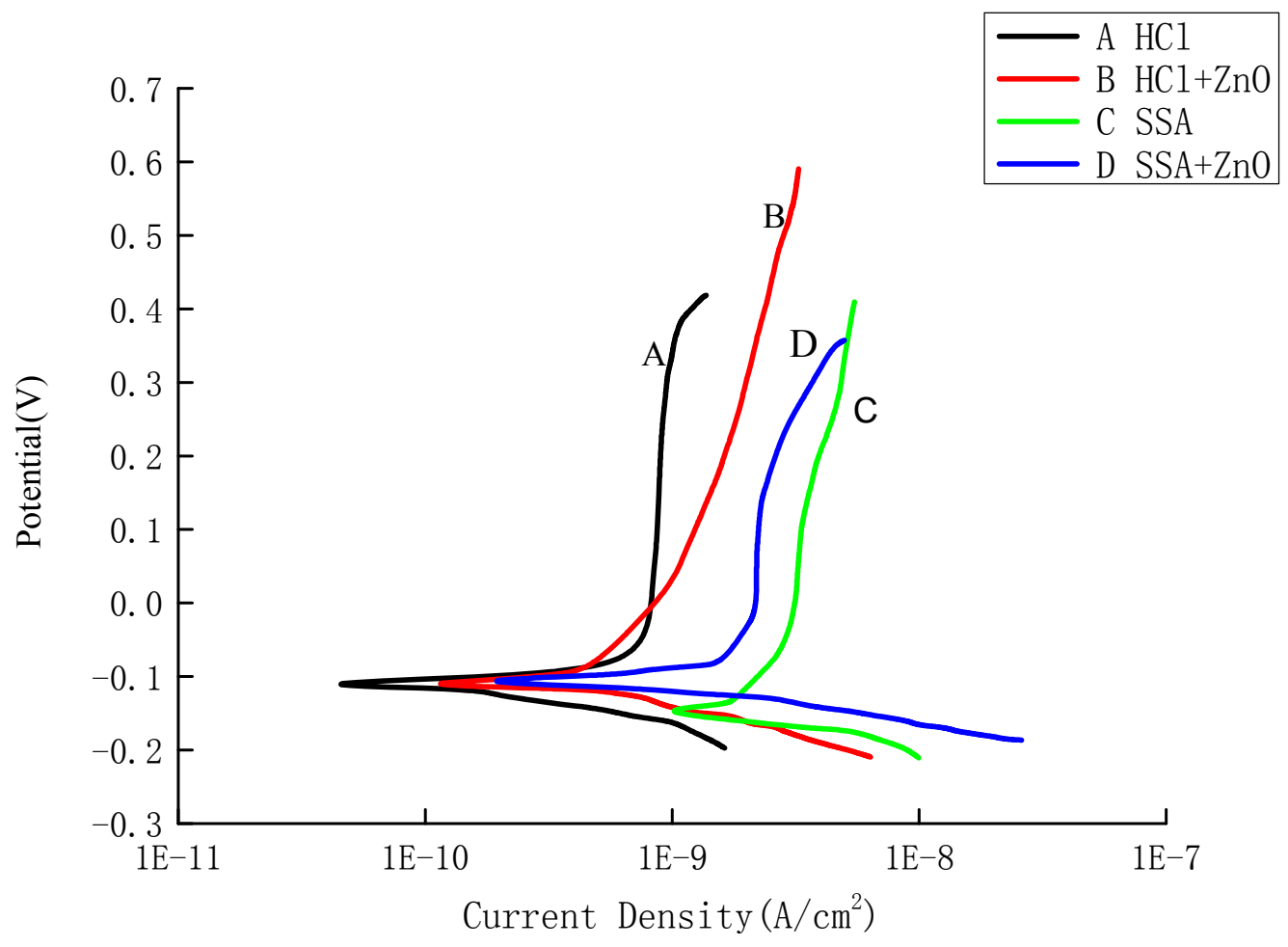

Fig.2 The Tafel plots of different composite coatings

\section{Conclusion}

(1) The conductivity of nano $\mathrm{ZnO} /$ polyaniline doped with organic proton acid is the highest.

(2) Compared with normal anticorrosive coating, Nano $\mathrm{ZnO} /$ polyaniline composite anticorrosive coating had lower corrosion current and larger corrosion potential, and shows better corrosion resistance. Corrosion resistant time of steel plate in $3.5 \mathrm{wt} \% \mathrm{NaCl}$ solution can be prolonged significantly, therefore, nano $\mathrm{ZnO} /$ polyaniline composite anticorrosive coating could be a very good anti-corrosion coatings.

(3) Among the four kinds of coating, the corrosion current of the nano $\mathrm{ZnO}$ /polyaniline coating 
doped with $\mathrm{HCl}$ was the lowest., the corrosion potential was the largest, and the corrosion resistance was the strongest.

\section{Acknowledgements}

This work was supported by the scientific research foundation (YQ14-420901) of Logistic Engineering College.

\section{References}

[1] J. Huang, X.Y. Peng, L.M. Yang and Y.W. Li: Development and Application of Materials, Forum Vol. 26 (2011), p. 89-91.(in Chinese)

[2] WANG jing-hui. Corrosion \& Protection in Petrochemical Industry, Forum Vol. 3 (2007) p. 31-31.(in Chinese)

[3] M.R. Huang, H.J. Yang, X.G. Li. Development and Application of Materials, Forum Vol. 20 (2007), p. 28-32.(in Chinese)

[4] S.L. Lin, D. Long, N.N. Tao, etc.. Development and Application of Materials. Forum Vol. 25 (2010), p. 36-39.(in Chinese)

[5] G.G. Wang. Total Corrosion. Forum Vol. 5 (2003), p. 26-28.(in Chinese)

[6] X.Y. Ye, Y.M. Zhou. Chemistry \& Bioengineering. Forum Vol. 27 (2010), p. 1-6.

[7] Z.W. Su, Y. Fang, Z. Li. New Chemical Materials. Forum Vol. 42 (2014), p. 172-174.

[8] L.C. Wang. NeiMengGu University. 2012.(in Chinese)

[9] C.B. Hu, Y.S. Zheng, Y.Q. Qing. China Plastics Industry. Forum Vol. 42 (2014), p. 86-90.(in Chinese)

[10]L. Ma, L.J. Feng, M.Y. Gan, etc.. CHINESE JOURNAL OF APPLIED CHEMISTRY. Forum Vol. 25 (2008), p. 142-146.(in Chinese)

[11]H. Huang, J.Y. Zhou, J.Q. XU. Journal of Chemical Engineering of Chinese Universities. Forum Vol. 23 (2009), p. 984-989.(in Chinese)

[12]H. Huang, J.Y. Zhou, J.Q. XU. Journal of Chemical Engineering of Chinese Universities. Forum Vol. 23 (2009,), p. 984-989.(in Chinese) 